\title{
Effects of HIV-1 protease on cellular functions and their potential applications in antiretroviral therapy
}

\author{
Hailiu Yang ${ }^{1}$, Joseph Nkeze ${ }^{2}$ and Richard Y Zhao $2,3,4^{*}$
}

\begin{abstract}
Human Immunodeficiency Virus Type 1 (HIV-1) protease inhibitors (PIs) are the most potent class of drugs in antiretroviral therapies. However, viral drug resistance to Pls could emerge rapidly thus reducing the effectiveness of those drugs. Of note, all current FDA-approved Pls are competitive inhibitors, i.e., inhibitors that compete with substrates for the active enzymatic site. This common inhibitory approach increases the likelihood of developing drug resistant HIV-1 strains that are resistant to many or all current PIs. Hence, new Pls that move away from the current target of the active enzymatic site are needed. Specifically, allosteric inhibitors, inhibitors that prohibit PR enzymatic activities through non-competitive binding to PR, should be sought. Another common feature of current PIs is they were all developed based on the structure-based design. Drugs derived from a structure-based strategy may generate target specific and potent inhibitors. However, this type of drug design can only target one site at a time and drugs discovered by this method are often associated with strong side effects such as cellular toxicity, limiting its number of target choices, efficacy, and applicability. In contrast, a cell-based system may provide a useful alternative strategy that can overcome many of the inherited shortcomings associated with structure-based drug designs. For example, allosteric Pls can be sought using a cell-based system without considering the site or mechanism of inhibition. In addition, a cell-based system can eliminate those Pls that have strong cytotoxic effect. Most importantly, a simple, economical, and easy-to-maintained eukaryotic cellular system such as yeast will allow us to search for potential Pls in a large-scaled high throughput screening (HTS) system, thus increasing the chances of success. Based on our many years of experience in using fission yeast as a model system to study HIV-1 Vpr, we propose the use of fission yeast as a possible surrogate system to study the effects of HIV-1 protease on cellular functions and to explore its utility as a HTS system to search for new PIs to battle HIV-1 resistant strains.
\end{abstract}

Keywords: HIV-1 protease, Structure-based design, Allosteric inhibitor, Antiretroviral therapy, Fission yeast, Cell-based high-throughput screening

\section{Introduction}

HIV/AIDS is one of the most devastating diseases in the world with approximately 34 million people living with HIV in 2010 and approximately 2.7 million new infections in the same year [1]. Use of antiretroviral therapy (ART) can successfully reduce Human Immunodeficiency Virus Type 1 (HIV-1) viral replication, of which HIV-1 protease (PR) inhibitors (PIs) are the most potent viral inhibitors.

\footnotetext{
* Correspondence: rzhao@som.umaryland.edu

${ }^{2}$ Department of Pathology, University of Maryland School of Medicine, Baltimore, MD, USA

${ }^{3}$ Department of Microbiology-Immunology, University of Maryland School of Medicine, 10 South Pine Street, MSTF 700, Baltimore, MD 21201-1192, USA Full list of author information is available at the end of the article
}

However, one of the major challenges in using ART is the emergence of viral drug resistance due to mutations in the $P R$ gene. Resistant mutations that accumulated during multiple ARTs may lead to cross drug resistance to most or all PIs [2-4], raising a possibility that multi-drug resistant viruses may ultimately outgrow the number of PIs available. Therefore, there is an urgent need to develop new PIs that are active against those drug-resistant HIV-1 PRs (dr-PRs). This review looks at the mechanisms in which HIV-1 PR alters host cellular functions such as apoptosis in $\mathrm{CD} 4^{+} \mathrm{T}$ lymphocytes, why PIs are such potent drugs, and how a eukaryotic cell-based high-throughput screening (HTS) system using the fission yeast (Schizosaccharomyces pombe) as

\section{Biomed Central}

(c) 2012 Yang et al.; licensee BioMed Central Ltd. This is an Open Access article distributed under the terms of the Creative Commons Attribution License (http://creativecommons.org/licenses/by/2.0), which permits unrestricted use, distribution, and reproduction in any medium, provided the original work is properly cited. 
a model organism may accelerate the drug discovery process and prevent dr-PRs from developing.

\section{Life cycle of HIV-1}

The life cycle of HIV-1 (Figure 1) comprises of the following distinct stages: 1) adsorption and fusion, 2) reverse transcription, 3) integration, 4) viral gene expression, 5) virus assembly and maturation, and 6) budding. The matured infections virion consists of two copies of genomic RNA and functional viral proteins: reverse transcriptase (RT), integrase (IN) and protease (PR). When the HIV -1 virion is uncoated into the targeted host cell such as a CD4 $4^{+}$T-lymphocyte, $\mathrm{RT}$ catalyzes the conversion of one copy of the genomic viral RNA into a double-stranded viral DNA (dsDNA) [5]. IN catalyzes its integration into the host chromosome to form a proviral DNA [5-8]. Using the host cellular system, copies of HIV-1 genomic material as well as shorter strands of messenger RNA (mRNA) are created. The mRNA strands are used as blueprint to make long chains of HIV-1 precursor proteins. The precursors are then cut by HIV-1 PR into smaller active proteins and assembled into mature virions. Following the assembly of viral RNA strands and smaller active proteins into a new viral particle, the virion buds from the host cell to infect another cell $[9,10]$.

During the virion assembly phase of HIV-1 replication, HIV-1 PR performs a series of 12 cleavages on the Gag, Gag-Pol and Nef polyprotein precursors [11-15]. These cleavages proceed in a sequential and highly specific manner to produce active viral enzymes (RT, PR and IN), viral structural proteins (capsid and nucleocaspid), and other viral factors essential for viral replication and infection $[11,14]$. Despite the specificity and sequential manner of these cleavages, the 12 proteolytic sites bear little resemblance to each other. There is currently the real substrate of HIV-1 PR and the factors governing substrate recognition $[11,12,16]$.

\section{HIV-1 protease}

PR belongs to the family of aspartic proteases. The structure of PR (Figure 2) is a homodimer and consists of subunits of 99 amino acid residues [5,9,17-22]. Each subunit is made up of nine $\beta$-strands and a single $\alpha$-helix. Four anti-parallel $\beta$ strands form the highly stable dimer interface which constitutes the active site $[5,19,20,22,23]$. The core of the active site is hydrophobic and contains two aspartic acid residues contributed by both subunits. Flexible anti-parallel $\beta$-sheets from both monomers form two flaps that cover the active site thereby restricting access to it [5,21,24-26]. In the free enzyme state, the flaps assume a semi-open conformation $[21,22,27,28]$ and with a ligand in the active site, they assume a closed conformation [5,22,26,29-31]. It has been reported that, a network of weakly polar interactions between the flaps keeps them in a semi-open conformation [21]. Two models have been used to explain the mechanisms of flap opening and closing. In the first model, the ligand forms a collision complex with HIV-1 PR in the open flap conformation as it enters the active site of the PR and then induces the flaps to close [32]. In the second model, the ligand approaches the HIV-1 PR in the semi-open flap

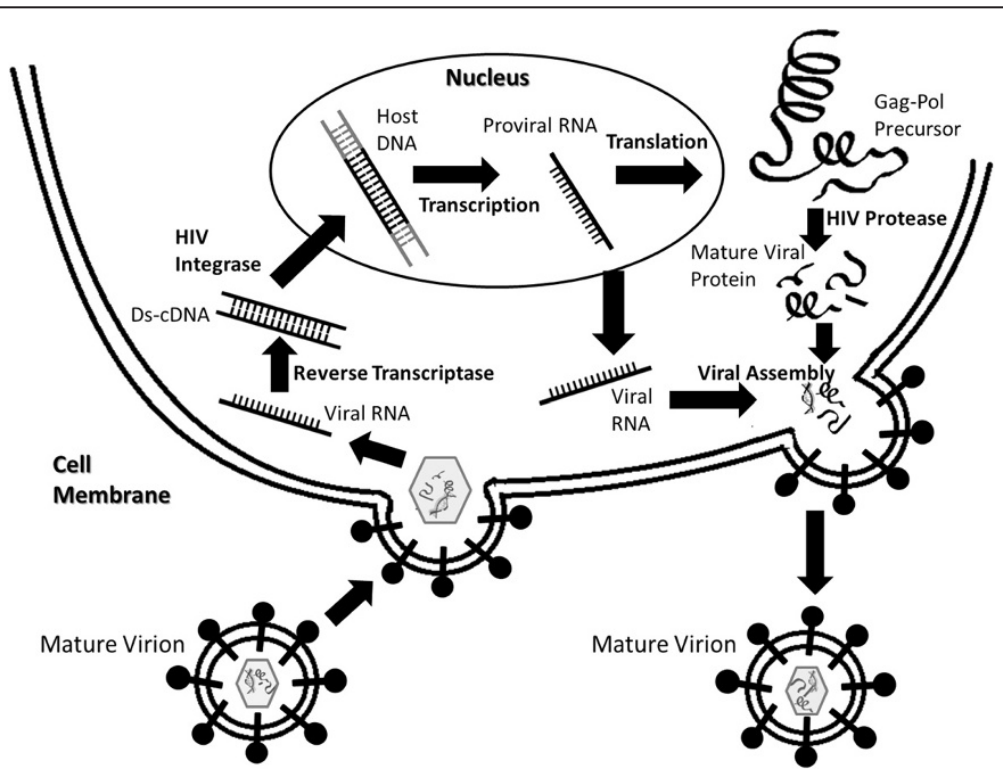

Figure 1 Life cycle of the HIV-1. Life cycle of HIV-1 occurs in 6 major steps: 1) adsorption and fusion of viral particle, 2) reverse transcription by Reverse Transcriptase, 3) integration of viral dsDNA into genomic DNA by Integrase, 4) expression of viral genes, 5) cleavage of Gag-pol and Gag precursor by HIV-1 PR and assembly of proteins into mature viral particle, and 6) budding of mature virion from host cell. 


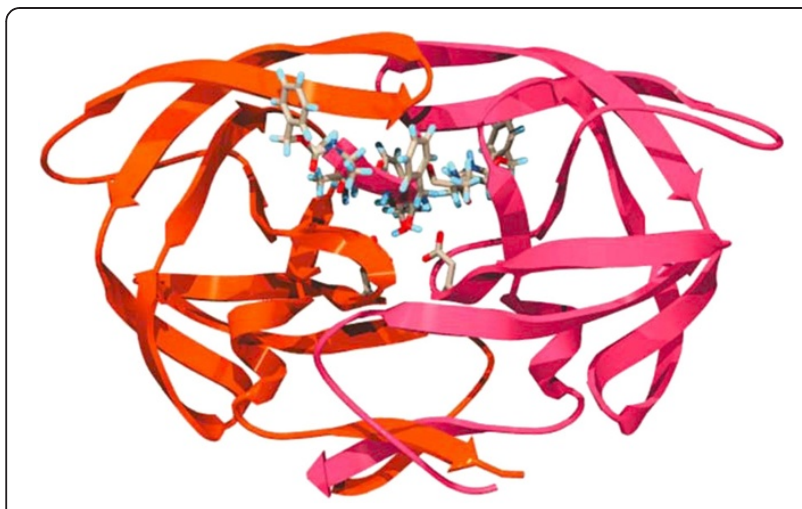

Figure 2 Structure of HIV-1 protease bound to TL-3, a competitive protease inhibitor. Figure was obtained with permission from [9].

conformation and then induces the flaps to adopt an open conformation as it enters the active site. The flaps then extend over the substrate and allow proteolysis to occur $[21,32,33]$. The PR cleavage site on the Gag and Gag-Pol precursor contain the unique amino acid sequences of PhePro and Tyr-Pro [5].

\section{Effects of HIV-1 PR on host cellular functions}

In addition to cleaving viral precursors, HIV-1 PR also cleaves host cell proteins. There is growing evidence that proteolysis and depletion of cellular proteins lead to both necrotic cell death and apoptotic cell death of the infected $\mathrm{CD}_{4}^{+} \mathrm{T}$-cell. This can occur through several pathways and contribute to the overall $\mathrm{CD} 4^{+} \mathrm{T}$-cell depletion in HIV/AIDS patients.

HIV-1 infection leads to necrotic/lytic cell death of the infected $\mathrm{CD} 4^{+} \mathrm{T}$-cell, resulting in $\mathrm{CD} 4^{+} \mathrm{T}$-cell depletion, a hallmark of HIV/AIDS [34,35]. However, the specific mechanisms of $\mathrm{CD}^{+}$T-cell depletion is elusive. Recently, CD4 ${ }^{+}$T-cell depletion has been directly associated with the actions of HIV-1 PR. Blanco et al. found that HIV-1 PR expression in COS7 monkey kidney cells resulted to visual changes associated with cell necrosis such as accumulation of cell debris, cellular swelling, vacuolization, and loss of plasma membrane integrity [36]. Treatment of HIV-1 PR expressing C8166 human lymphocytes and COS7 cells with the protease inhibitor Saquinavir inhibited these necrotic effects [36,37]. Furthermore, removal of Saquinavir from $P R$-expressing C8166 cells resulted to reactivation of HIV-1 PR and cellular necrosis [37]. These results suggest that the necrotic process is a direct result of the proteolysis of cellular proteins by HIV-1 PR. The exact mechanism(s) leading to necrotic cell death is currently unclear.

HIV-1 PR proteolysis of cytoskeletal proteins has been linked to necrotic or apoptotic cell death. HIV-1 PR has been shown in vitro to cleave many cytoskeletal proteins, including actin, desmin, myosin, tropomyosin, troponin $\mathrm{C}$, vimentin, alzheimer amyloid precursor protein, and glial fibrillary acidic protein [38-43]. Of these cytoskeletal proteins, vimentin is a known substrate for HIV-1 PR in vivo. Injection of purified HIV-1 PR into human fibroblastic cells resulted to in disruption of stress fibers, collapse of the cytoplasmic vimentin intermediate filaments, and changes in nuclear morphology and chromatin organization [43]. The cytoplasmic structural changes are a direct result of cleavage of cytoplasmic vimentin and other structural proteins by HIV-1 PR [43]. Changes in nuclear morphology and chromatin organization are believed to be initiated by an $\mathrm{N}$ terminal fragment of cleaved vimentin [39]. When HIV-1 PR cleaves vimentin, it produces an N-terminal fragment that, unlike uncleaved vimentin, is able to infiltrate the nucleus and cause structural changes via a mechanism currently unclear [39]. These cellular effects are certainly detrimental and likely to be involved in either necrosis or apoptosis. However, there is currently inadequate evidence to support whether cleavage of these cytoskeletal proteins triggers cell death and if so, how.

HIV-1 PR induces CD4 ${ }^{+}$T-cell apoptosis by decreasing concentration of cellular protein Bcl-2 [44,45], an antiapoptotic member of the Bcl-2 protein family [46]. Strack et al. found that prior to apoptosis in several cell lines induced to express HIV-1 PR, intact Bcl-2 was undetectable and fragmented Bcl-2 level was abnormally high [44]. Further experiments showed that ectopic expression of $b c l-2$ in $P R$-expressing lymphocytes in vivo and in vitro decreased apoptosis and suppressed HIV-1 $\mathrm{PR}$ activity, indicating that $\mathrm{Bcl}-2$ protects cells from the cytotoxic effects of HIV-1 PR and apoptosis [44]. Additionally, cells expressing bcl-2 in vitro and in vivo showed lower rates of apoptosis compared to cells that did not, suggesting that Bcl-2 depletion is a requirement for PR-induced apoptosis [44]. The loss of anti-apoptotic function of the cleaved $\mathrm{Bcl}-2$ is likely due to removal of the $\mathrm{BH} 3$ and $\mathrm{BH} 4$ domain following cleavage between residue 112 and 113 [44,47]. Normally, Bcl-2 inhibits apoptosis by dimerizing with pro-apoptotic factors of the Bcl-2 protein family. Both BH3 (ligand domain) and BH4 (cell death protecting domain) are essential for this function: $\mathrm{BH} 3$ is responsible for binding to $\mathrm{BH} 3$ containing pro-apoptotic factors [48] and $\mathrm{BH} 4$ is responsible for interacting with Raf kinases $[47,49]$. Hence, removal of these domains will most likely result to a loss of $\mathrm{Bcl}-2$ function, leading to apoptosis.

HIV-1 PR also induces apoptotic cell death via the proteolysis of Procaspase 8 between residue 355 and 356 to form Casp8p41, a truncated form of Procaspase 8 that signals cell death [50-52]. The exact mechanism by which Casp8p41 causes apoptosis has not been elucidated, but several key players have been identified. First, cleavage of Procaspase 8 into Casp8p41 is essential for this apoptosis-inducing 
pathway. When HIV-1 PR is transfected into I.9.2 cells, a T-lymphocyte cell line producing cleavage-resistant Procaspase 8 , apoptosis is drastically reduced compared to cells producing wild-type Procaspase 8 [52]. Second, Casp8p41 acts through the intrinsic/mitochondrial apoptotic pathway, a pathway in which internal stimuli induce mitochondrial release of pro-apoptotic proteins to carry out apoptosis. Casp8p41 localizes in the mitochondria, the initiation site of the intrinsic apoptotic pathway [53]. In addition, Casp8p41 pathway requires Caspase 9 and Bax/ Bak; casp8p41 transfection in cells with caspase 9 or bax/ bak knockout causes minimal cell death compared to non-knockout cells [53]. Caspase 9 is an initiator caspase of the intrinsic apoptotic pathway that activates Procaspase 3 into Caspase 3, the most important executioner caspase [46]. Bax and Bak are both pro-apoptotic members of the Bcl-2 protein family that govern mitochondrial membrane permeability [46], which activates the intrinsic apoptotic pathway with Bax and Bak being essential regulators. Evidence suggests that the Casp8p41 pathway is a major cause of cell death associated with HIV-1 PR. Lymphoid tissues from HIV-1 infected patients showed that cells with Casp8p41, experienced a drastically increased rate of apoptosis and higher levels of proapoptotic factor Caspase 3 compared to cells void of Casp8p41 [50,52]. Furthermore, inhibition of HIV-1 PR cleavage of Procaspase 8 into Casp8p41 in I.9.2 cells (described above), resulted to in a large reduction of cell death in cells transfected with HIV-1 PR [52].

It is clear that HIV-1 PR's role is not limited to the cleavage of viral precursor proteins and assembly of the mature virions. HIV-1 PR cleaves an array of cellular proteins and contributes to HIV-induced cytotoxicity through several pathways.

\section{Current state of HIV therapy}

Currently, the gold standard of HIV treatment is highly active antiretroviral therapy (HAART). HAART is a cocktail of drugs from several classes of antiretroviral drugs (ARVs), each of which inhibits one step of the HIV-1 life cycle. For example, PIs prevent protease from cleaving the Gag and Gag-Pol precursor polyproteins, thus inhibiting the assembly and maturation of the viral particle; RT inhibitors prevent conversion of viral genomic RNA into viral DNA, thus stopping viral DNA integration into host chromosome. The multiple ARVs present in HAART work together to suppress HIV-1 at multiple stages of the viral life cycle. For many years, HAART has been proven to effectively decrease viral load and increase $\mathrm{CD}_{4}^{+} \mathrm{T}$-cell count, thus improving the quality of life of HIV/AIDS patients. Recent reports show that a HIV-1 infected patient can expect to have a close-to-normal life span if the virus is diagnosed early and treated with adequate HAART $[54,55]$.

\section{HIV-1 protease inhibitors}

Of all the ARV drugs, PIs are the most potent because they improve the clinical outcome of HIV patients in three important ways. First, PIs suppress HIV-1 PR by preventing the assembly of mature virion, thus preventing viral replication and decreasing viral load. Second, PIs inhibit PR cleavage of host cell proteins (described above), which reduces PR-related cytotoxicity, apoptosis, and necrosis in infected host cells. Third, PIs have anti-apoptotic effects via a mechanism not directly related to HIV-1 PR suppression. This emerging area of research will not be discussed in this paper, but is extensively reviewed in [56,57]. These three major benefits of PIs make them essential to any HAART.

Because PIs are so important to HAART, the development of viral resistance to PIs may have dire public health consequences. Currently, there are eleven FDA approved PIs on the market [58]. These PIs all belong to the same mechanistic class of competitive inhibitors: inhibitors that bind to the active site of PR to prevent substrate association $[59,60]$. One major problem with this commonality among PIs is that $P R$ mutations in the active site may interfere with active site geometry and lead to cross-resistance to multiple or all protease inhibitors $[2-4,61]$. To combat this problem, we need to consider potential alternative strategies such as developing allosteric PIs, i.e., non-competitive inhibitors that inhibit HIV-1 PR at a site other than the active site. The existing $P R$ mutants resistant to the competitive PIs are less likely to confer cross-resistance to the allosteric PIs because allosteric inhibitors do not compete with substrates for the active site.

One class of promising allosteric inhibitor is the compounds that interact with the flaps covering the HIV-1 PR active site (Figure 2). Alteration of the flaps interferes with substrate docking to reduce PR activity. Polyoxometalates (POM) are a class of large inorganic flap-binding allosteric inhibitors [62]. Although POMs are potent PIs, they were initially found to be too toxic for clinical use [63]. Recent research has been focused on modifying the functional groups of POMs in a way that maintains its potency while reducing its cytotoxicity [64]. A particularly promising group of candidate PIs are the C3-substituted cyclopentyltetrahydrofuranyl (Cp-THF) compounds, a recently designed group of flap-binding small molecule inhibitors $[65,66]$. Ghosh et al. found that several Cp-THFs effectively inhibit a panel of dr-PRs in vitro, demonstrating their potential to combat dr-PRs $[65,66]$.

Another allosteric PI class being investigated are dimerization inhibitors. Dimerization inhibitors inhibit HIV-1 PR by binding to the dimerization interface and preventing the formation of the active PR homodimer. Bouras et al. first reported a dimerization inhibitor that interfered with the $\beta$-sheet dimerization interface of the 
HIV-1 PR monomer [67]. Chmielewski et al. have also been developing a dimerization inhibitor design [68-72] that cross-links the interfacial peptides of HIV-1 PR to prevent formation of the active homodimer protein [71].

Significant progress has been made towards designing allosteric inhibitors, but we currently have no FDAapproved allosteric inhibitor. Like current FDA-approved competitive inhibitors, all allosteric inhibitors in development were discovered through a structure-based design. In a structure-based design, inhibitors are selected, using structural data or computational predictions, to fit a specified site on the target protein and assayed in vitro for binding affinity. The inhibitors are then improved upon by a trial-and-error process in which structural modifications are made, assayed for binding affinity, and compared. After the in vitro potency of the drug has been demonstrated, the drug is then tested in vivo. There are several limitations to this system. The structure-based method requires extensive knowledge of the structure of the substrate and inhibitor, limiting what it can screen for. Since a structure-based design focuses on fitting an inhibitor to a specific site on the protein (usually the active site), it can only look for inhibitors to one site at a time. Finally, the structural design may generate PIs that are target specific and potent, but come with strong adverse effect such as cellular toxicity, thus diminishing their efficacy and applicability.

\section{Cell-based drug screenings and future perspectives}

A cell-based system to screen for PIs holds several advantages over a structure-based design. First, since a cell-based system does not require structural knowledge of the target protein, it is not restricted by the availability of structural data of proteins such as dr-PRs with conformational changes from the wild-type PR. Second, allosteric PIs could be sought in a cell-based system purely based on their inhibitory effect of HIV-1 PRinduced cell death without considering the site of inhibition. This is because a cell-based HTS looks at results at the cellular level, allowing it to target the whole HIV-1 protease. What this means is that a cell-based system can potentially identify all types of PIs at once, regardless of their binding site or mechanism of action. The third distinctive advantage of a cell-based system over structurebased designs is that a cell-based system can eliminate any compounds that have strong cytotoxic effect. Most importantly, a simple, economical, and easy-to-maintained cellular system will allow searching for potential PIs in a large-scaled HTS system, increasing our chances of success. Thus, cell-based drug screening systems may be a useful alternative strategy that will overcome many of the inherited shortcomings associated with the structure-based drug design and identify new PIs that would be difficult to develop using structure-based designs.

There are currently several cell-based PI screening systems using Escherichia coli (E. coli) $[73,74]$ or human cells [75-77]. All of these systems are capable of screening for HIV-1 PR activity and two of them also are capable of screening for cytotoxicity [74,76]. Cheng et al. developed a cell-based assay model for PR-induced cytotoxicity by expressing HIV-1 PR in E. coli [74], an organism that shows cytotoxicity upon $P R$ expression, just like in mammalian cells $[78,79]$. Fuse et al. expressed HIV-1 $P R$ in a chimeric protein along with green fluorescence protein in a novel human kidney cell line (E-PR293) to assay for both PR levels and cytotoxicity [76]. These systems are useful, but neither is ideal for cell-based HTS. E. coli is a prokaryotic organism that is different from a mammalian cell in many ways, so results obtained from E. coli may not translate well to humans. E-PR293 is a human cell line, which is expensive and time-consuming to maintain. Hence, the system developed by Fuse at al. will make a good confirmatory assay, but may be too expensive for cell-based HTS. Therefore, we are still in need of a suitable model organism for a viable cell-based HTS system.

An ideal model organism for PR studies should: 1) be easy to maintain and manipulate, 2) share fundamental cellular features and processes with mammalian cells, and 3) have cellular response to PR similar to cellular effects of PR in mammalian cells. Fission yeast possesses many of these properties. Specifically, fission yeast is a unicellular organism that is very easy to grow and manipulate in the laboratory. It typically divides every $3-4$ hours at $30^{\circ} \mathrm{C}$ with active agitation compared to 24 hours for human cell lines. Despite its simplicity, fission yeast, as a eukaryotic organism, shares very similar fundamental cellular features and processes as mammalian cells. For example, it has similar cell cycles as cells of higher eukaryotes [80,81]. In addition, fission yeast contains a splicing mechanism that is able to remove introns from genes of higher eukaryotes and mammals [81-83]. Since fission yeast is capable of post-translational modification (e.g., phosphorylation and acetylation), the heterogeneous proteins produced by fission yeast are very close to their natural forms in mammalian cells $[80,82,83]$.

Based on the above mentioned properties, a fission yeast cell-based HTS system may be a feasible alternative for future screenings of PIs. Its feasibility is supported by the fact that fission yeast has been used extensively as a model system to study HIV-1 viral protein R (Vpr) during HIV-1 infection \{reviewed in [84-86]\}. For instance, $\mathrm{Vpr}$ induces similar cellular changes in both fission yeast and human cells [87], which include: 1) cell cycle G2/M arrest $[86,88,89], 2)$ cytoplasm to nuclear transport of viral preintergration complex [81,89], and 3) induction cell death and apoptosis [88-90]. Taking advantage of Vpr-induced 
cell cycle arrest and cell killing in fission yeast, Benko et al. has established a HTS system for screening HIV-1 inhibitors and cellular suppressors. In a pilot study, they have shown that this cell-based HTS is capable of picking out a Vpr inhibitor from a chemical drug library [91]. This HTS system is currently being employed by the National Institutes of Health Chemical Genomics Center to screen for $\mathrm{Vpr}$ inhibitors.

As for the cellular effects of HIV-1 PR, there is currently no published data on whether HIV-1 PR behaves similarly in fission yeast and in mammalian cells. However, based on our many years' experience in studying HIV-1 Vpr in fission yeast cells, we have reason to believe that fission yeast should be a reasonable model to study HIV-1 PR as well. Specifically, since expression of HIV-1 Vpr induces cell death via apoptosis in both fission yeast and mammalian cells [86-90], it is likely that expression of HIV-1 PR, which also causes cell death and apoptosis in mammalian cells, may have a similar effects in fission yeast and mammalian cells. Blanco et al. showed that expression of HIV-1 PR in budding yeast (Saccharomyces cerevisiae) causes cell death [36], further supporting the idea that HIV-1 $P R$ expression should have a similar effect in fission yeast.

It should be mentioned that although fission yeast may serve as a reasonably good model organism for HTS of PIs, it certainly has its own limitations. For example, fission yeast cells have cell walls but human cells do not, which may limit input of large molecule into the cell. In addition, fission yeast cells only have 3 chromosomes while human cells have 23 pairs. Hence, while results obtained from studying PR and PI in fission yeast are more translatable to humans than many organisms such as $E$. coli, confirmatory test in human cell system are still needed to validate their clinical efficacy.

Our current and future effort will focus on the studying and characterization of HIV-1 PR in fission yeast and to further explore its utility as a HTS system to search for new PIs.

\section{Conclusion}

In this review, we have shown that HIV-1 PR cleaves viral proteins as well as host cell proteins. The cleavage of host cell proteins results in cell death via several necrotic and apoptotic pathways, possibly leading to depletion of $\mathrm{CD} 4^{+}$ T-cells. Thus, PIs are particularly useful as ARVs not only because they inhibit viral replication but also because they rescue host immune cells. One of the downsides of current PIs is the rapid emergence of drug resistance due in part to the fact that all current PIs were designed against the same site on HIV-1 PR: the enzymatic site. To combat drug resistance and avoid multi-drug resistance, allosteric PIs are needed. There are currently several promising allosteric PI candidates. However, development of those drugs has been slow because of the inherited limitations of their structure-based design. Alternatively, cellbased drug screening system could potentially be a good alternative approach that is not limited by the systematic shortcomings of the structure-based design. However, the current challenge associated with using a cell-based system is that there is no suitable model organism to carry out this assay in an economically feasible way. Fission yeast might be a good alternative because it is a single-cell eukaryotic organism. Hence, it is easy to maintain and manipulate in the laboratory, amendable for large-scale HTS, and most importantly, it shares many fundamental cellular features and processes with mammalian cells. Thus we propose that future efforts should focus on studying and characterizing HIV-1 PR in fission yeast and further exploring its potential application as a HTS system for new PIs.

\section{Abbreviations}

ARV: Anti-retroviral drug; Cp-THF: C3-substituted

cyclopentyltetrahydrofuranyl; dr-PR: Drug resistant HIV-1 protease; dsDNA: Double stranded DNA; FDA: Food and Drug Administration; HAART: Highly active antiretroviral therapy; HIV-1: Human Immunodeficiency Virus Type-1; HTS: High throughput screening; IN: Integrase; mRNA: Messenger RNA; PI: Protease inhibitor; POM: Polyoxometalates; PR: Protease; RT: Reverse transcriptase; Vpr: Viral protein R.

\section{Competing interest}

The authors declare that they have no competing interests.

\section{Authors' contribution}

HY designed and drafted the manuscript. JN drafted part of the manuscript and helped to revise the manuscript. RZ designed and revised the manuscript. All authors read and approved the final manuscript.

\section{Acknowledgements}

The authors would like to thank Dr. Ge Li and Dong Liang for critical reading and comments on this manuscript. Adam Zhao, Tiffney Teng, John Luo and Allen Aye provided useful suggestions. This work was supported in part by funding from the University of Maryland Medical Center and NIH-NINDS-R21NS063880 (RZ)

\section{Author details}

'University of Maryland School of Medicine, Baltimore, MD, USA

${ }^{2}$ Department of Pathology, University of Maryland School of Medicine, Baltimore, MD, USA. ${ }^{3}$ Department of Microbiology-Immunology, University of Maryland School of Medicine, 10 South Pine Street, MSTF 700, Baltimore, MD 21201-1192, USA. ${ }^{4}$ Institute of Human Virology, University of Maryland School of Medicine, 10 South Pine Street, MSTF 700, Baltimore, MD 21201-1192, USA

Received: 10 August 2012 Accepted: 31 August 2012

Published: 12 September 2012

\section{References}

1. WHO: Global HIV/AIDS Response: Epidemic update and health sector progress towards Universal Access. In Progress Report 2011. Geneva, Switzerland: World Health Organization (WHO); 2011:1-224.

2. Logsdon BC, Vickrey JF, Martin P, Proteasa G, Koepke Jl, Terlecky SR, Wawrzak Z, Winters MA, Merigan TC, Kovari LC: Crystal structures of a multidrug-resistant human immunodeficiency virus type 1 protease reveal an expanded active-site cavity. J Virol 2004, 78:3123-3132.

3. Palmer S, Shafer RW, Merigan TC: Highly drug-resistant HIV-1 clinical isolates are cross-resistant to many antiretroviral compounds in current clinical development. Aids 1999, 13:661-667.

4. Rhee SY, Taylor J, Fessel WJ, Kaufman D, Towner W, Troia P, Ruane P, Hellinger J, Shirvani V, Zolopa A, Shafer RW: HIV-1 protease mutations and 
protease inhibitor cross-resistance. Antimicrob Agents Chemother 2010, 54:4253-4261.

5. Imamichi T: Action of anti-HIV drugs and resistance: reverse transcriptase inhibitors and protease inhibitors. Curr Pharm Des 2004, 10:4039-4053.

6. Dayam R, Neamati N: Small-molecule HIV-1 integrase inhibitors: the 2001-2002 update. Curr Pharm Des 2003, 9:1789-1802.

7. Neamati N, Marchand C, Pommier Y: HIV-1 integrase inhibitors: past, present, and future. Adv Pharmacol 2000, 49:147-165.

8. Pommier $Y$, Marchand C, Neamati N: Retroviral integrase inhibitors year 2000: update and perspectives. Antiviral Res 2000, 47:139-148.

9. Brik A, Wong CH: HIV-1 protease: mechanism and drug discovery. Org Biomol Chem 2003, 1:5-14.

10. Hoggard PG, Owen A: The mechanisms that control intracellular penetration of the HIV protease inhibitors. J Antimicrob Chemother 2003, 51:493-496

11. Perez MA, Fernandes PA, Ramos MJ: Substrate recognition in HIV-1 protease: a computational study. J Phys Chem B 2010, 114:2525-2532.

12. Pettit SC, Clemente JC, Jeung JA, Dunn BM, Kaplan AH: Ordered processing of the human immunodeficiency virus type $1 \mathrm{GagPol}$ precursor is influenced by the context of the embedded viral protease. J Virol 2005, 79:10601-10607

13. Krausslich HG, Ingraham RH, Skoog MT, Wimmer E, Pallai PV, Carter CA: Activity of purified biosynthetic proteinase of human immunodeficiency virus on natural substrates and synthetic peptides. Proc Natl Acad Sci U S A 1989, 86:807-811.

14. De Oliveira T, Engelbrecht S, Janse van Rensburg E, Gordon M, Bishop K, Zur Megede J, Barnett SW, Cassol S: Variability at human immunodeficiency virus type 1 subtype $C$ protease cleavage sites: an indication of viral fitness? J Virol 2003, 77:9422-9430.

15. Barrie KA, Perez EE, Lamers SL, Farmerie WG, Dunn BM, Sleasman JW, Goodenow MM: Natural variation in HIV-1 protease, Gag p7 and p6, and protease cleavage sites within gag/pol polyproteins: amino acid substitutions in the absence of protease inhibitors in mothers and children infected by human immunodeficiency virus type 1. Virology 1996, 219:407-416

16. Ridky TW, Cameron CE, Cameron J, Leis J, Copeland T, Wlodawer A, Weber IT, Harrison RW: Human immunodeficiency virus, type 1 protease substrate specificity is limited by interactions between substrate amino acids bound in adjacent enzyme subsites. J Biol Chem 1996, 271:4709-4717.

17. Pearl LH, Taylor WR: A structural model for the retroviral proteases. Nature 1987, 329:351-354

18. Piana S, Carloni P, Rothlisberger U: Drug resistance in HIV-1 protease: Flexibility-assisted mechanism of compensatory mutations. Protein $\mathrm{SCl}$ 2002, 11:2393-2402.

19. Todd MJ, Freire E: The effect of inhibitor binding on the structural stability and cooperativity of the HIV-1 protease. Proteins 1999, 36:147-156.

20. Todd MJ, Semo N, Freire E: The structural stability of the HIV-1 protease. J Mol Biol 1998, 283:475-488

21. Toth G, Borics A: Flap opening mechanism of HIV-1 protease. J Mol Graph Model 2006, 24:465-474.

22. Velazquez-Campoy A, Muzammil S, Ohtaka H, Schon A, Vega S, Freire E: Structural and thermodynamic basis of resistance to HIV-1 protease inhibition: implications for inhibitor design. Curr Drug Targets Infect Disord 2003, 3:311-328.

23. Luque I, Freire E: Structural stability of binding sites: consequences for binding affinity and allosteric effects. Proteins 2000, Suppl 4: $63-71$.

24. Lapatto R, Blundell T, Hemmings A, Overington J, Wilderspin A, Wood S, Merson JR, Whittle PJ, Danley DE, Geoghegan KF, et al: X-ray analysis of HIV-1 proteinase at 2.7 A resolution confirms structural homology among retroviral enzymes. Nature 1989, 342:299-302.

25. Spinelli S, Liu QZ, Alzari PM, Hirel PH, Poljak RJ: The threedimensional structure of the aspartyl protease from the HIV-1 isolate BRU. Biochimie 1991, 73:1391-1396.

26. Wlodawer A, Miller M, Jaskolski M, Sathyanarayana BK, Baldwin E, Weber IT, Selk LM, Clawson L, Schneider J, Kent SB: Conserved folding in retroviral proteases: crystal structure of a synthetic HIV-1 protease. Science 1989, 245:616-621.

27. Louis JM, Dyda F, Nashed NT, Kimmel AR, Davies DR: Hydrophilic peptides derived from the transframe region of Gag-Pol inhibit the HIV-1 protease. Biochemistry 1998, 37:2105-2110.
28. Prabu-Jeyabalan M, Nalivaika E, Schiffer CA: How does a symmetric dimer recognize an asymmetric substrate? A substrate complex of HIV-1 protease. J Mol Biol 2000, 301:1207-1220.

29. Coffin JM: HIV population dynamics in vivo: implications for genetic variation, pathogenesis, and therapy. Science 1995, 267:483-489.

30. Miller M, Schneider J, Sathyanarayana BK, Toth MV, Marshall GR, Clawson L, Selk L, Kent SB, Wlodawer A: Structure of complex of synthetic HIV-1 protease with a substrate-based inhibitor at $2.3 \mathrm{~A}$ resolution. Science 1989, 246:1149-1152.

31. Rick SW, Erickson JW, Burt SK: Reaction path and free energy calculations of the transition between alternate conformations of HIV-1 protease. Proteins 1998, 32:7-16.

32. Scott WR, Schiffer CA: Curling of flap tips in HIV-1 protease as a mechanism for substrate entry and tolerance of drug resistance. Structure 2000, 8:1259-1265.

33. Collins JR, Burt SK, Erickson JW: Flap opening in HIV-1 protease simulated by 'activated' molecular dynamics. Nat Struct Biol 1995, 2:334-338.

34. Levy JA: Pathogenesis of human immunodeficiency virus infection. Microbiol Rev 1993, 57:183-289.

35. Voss TG, Fermin CD, Levy JA, Vigh S, Choi B, Garry RF: Alteration of intracellular potassium and sodium concentrations correlates with induction of cytopathic effects by human immunodeficiency virus. J Virol 1996, 70:5447-5454.

36. Blanco R, Carrasco L, Ventoso I: Cell killing by HIV-1 protease. J Biol Chem 2003, 278:1086-1093.

37. Ventoso I, Navarro J, Munoz MA, Carrasco L: Involvement of HIV-1 protease in virus-induced cell killing. Antiviral Res 2005, 66:47-55.

38. Shoeman RL, Honer B, Stoller TJ, Kesselmeier C, Miedel MC, Traub P, Graves MC: Human immunodeficiency virus type 1 protease cleaves the intermediate filament proteins vimentin, desmin, and glial fibrillary acidic protein. Proc Natl Acad Sci U S A 1990, 87:6336-6340.

39. Shoeman RL, Huttermann C, Hartig R, Traub P: Amino-terminal polypeptides of vimentin are responsible for the changes in nuclear architecture associated with human immunodeficiency virus type 1 protease activity in tissue culture cells. Mol Biol Cell 2001, 12:143-154.

40. Konvalinka J, Litterst MA, Welker R, Kottler H, Rippmann F, Heuser AM Krausslich HG: An active-site mutation in the human immunodeficiency virus type 1 proteinase (PR) causes reduced PR activity and loss of PRmediated cytotoxicity without apparent effect on virus maturation and infectivity. J Virol 1995, 69:7180-7186.

41. Tomasselli AG, Hui JO, Adams L, Chosay J, Lowery D, Greenberg B, Yem A, Deibel MR, Zurcher-Neely H, Heinrikson RL: Actin, troponin C, Alzheimer amyloid precursor protein and pro-interleukin 1 beta as substrates of the protease from human immunodeficiency virus. J Biol Chem 1991, 266:14548-14553.

42. Shoeman RL, Sachse C, Honer B, Mothes E, Kaufmann M, Traub P: Cleavage of human and mouse cytoskeletal and sarcomeric proteins by human immunodeficiency virus type 1 protease. Actin, desmin, myosin, and tropomyosin. Am J Pathol 1993, 142:221-230.

43. Honer B, Shoeman RL, Traub P: Human immunodeficiency virus type 1 protease microinjected into cultured human skin fibroblasts cleaves vimentin and affects cytoskeletal and nuclear architecture. J Cell Sci 1991, 100(Pt 4):799-807.

44. Strack PR, Frey MW, Rizzo CJ, Cordova B, George HJ, Meade R, Ho SP, Corman J, Tritch R, Korant BD: Apoptosis mediated by HIV protease is preceded by cleavage of Bcl-2. Proc Natl Acad Sci U S A 1996, 93: 9571-9576.

45. Korant BD, Strack P, Frey MW, Rizzo CJ: A cellular anti-apoptosis protein is cleaved by the HIV-1 protease. Adv Exp Med Biol 1998, 436:27-29.

46. Elmore S: Apoptosis: a review of programmed cell death. Toxicol Pathol 2007, 35:495-516.

47. Vlahakis SR: Cell Death In HIV Infection: gp120. In Cell Death During HIV Infection. Edited by Badley AD. Florida: CRC Press, Taylor and Francis Group; 2006:95-108.

48. Cory S, Huang DC, Adams JM: The Bcl-2 family: roles in cell survival and oncogenesis. Oncogene 2003, 22:8590-8607.

49. Rapp UR, Rennefahrt U, Troppmair J: Bcl-2 proteins: master switches at the intersection of death signaling and the survival control by Raf kinases. Biochim Biophys Acta 2004, 1644:149-158.

50. Nie Z, Bren GD, Vlahakis SR, Schimnich AA, Brenchley JM, Trushin SA, Warren S, Schnepple DJ, Kovacs CM, Loutfy MR, Douek DC, Badley AD: Human 
immunodeficiency virus type 1 protease cleaves procaspase 8 in vivo. $J$ Virol 2007, 81:6947-6956

51. Nie Z, Phenix BN, Lum JJ, Alam A, Lynch DH, Beckett B, Krammer PH, Sekaly RP, Badley AD: HIV-1 protease processes procaspase 8 to cause mitochondrial release of cytochrome $c$, caspase cleavage and nuclear fragmentation. Cell Death Differ 2002, 9:1172-1184.

52. Nie Z, Bren GD, Rizza SA, Badley AD: HIV Protease Cleavage of Procaspase 8 is Necessary for Death of HIV-Infected Cells. Open Virol J 2008, 2:1-7.

53. Sainski AM, Natesampillai S, Cummins NW, Bren GD, Taylor J, Saenz DT, Poeschla EM, Badley AD: The HIV-1-specific protein Casp8p41 induces death of infected cells through Bax/Bak. J Virol 2011, 85:7965-7975.

54. Nakagawa F, Lodwick RK, Smith CJ, Smith R, Cambiano V, Lundgren JD, Delpech V, Phillips AN: Projected life expectancy of people with HIV according to timing of diagnosis. Aids 2012, 26:335-343.

55. Hartman TL, Buckheit RW Jr: The Continuing Evolution of HIV-1 Therapy: Identification and Development of Novel Antiretroviral Agents Targeting Viral and Cellular Targets. Mol Biol Int 2012, 2012:401965.

56. Vlahakis SR, Bennett SA, Whitehead SN, Badley AD: HIV protease inhibitors modulate apoptosis signaling in vitro and in vivo. Apoptosis 2007, 12:969-977

57. Rizza SA, Badley AD: HIV protease inhibitors impact on apoptosis. Med Chem 2008, 4:75-79.

58. FDA-Approved Anti-HIV Medications. http://www.aidsinfo.nih.gov/contentfiles/ ApprovedMedstoTreatHIV_FS_en.pdf.

59. Anderson J, Schiffer C, Lee SK, Swanstrom R: Viral protease inhibitors. Handb Exp Pharmacol 2009, 189:85-110.

60. Chang MW, Giffin MJ, Muller R, Savage J, Lin YC, Hong S, Jin W, Whitby LR, Elder JH, Boger DL, Torbett BE: Identification of broad-based HIV-1 protease inhibitors from combinatorial libraries. Biochem J 2010, 429: 527-532.

61. Agniswamy J, Shen $\mathrm{CH}$, Aniana A, Sayer JM, Louis JM, Weber IT: HIV-1 protease with 20 mutations exhibits extreme resistance to clinical inhibitors through coordinated structural rearrangements. Biochemistry 2012, 51:2819-2828.

62. Judd DA, Nettles JH, Nevins N, Snyder JP, Liotta DC, Tang J, Ermolieff J, Schinazi RF, Hill CL: Polyoxometalate HIV-1 protease inhibitors. A new mode of protease inhibition. J Am Chem Soc 2001, 123:886-897.

63. Moskovitz BL: Clinical trial of tolerance of HPA-23 in patients with acquired immune deficiency syndrome. Antimicrob Agents Chemother $1988,32: 1300-1303$.

64. Flutsch A, Schroeder T, Grutter MG, Patzke GR: HIV-1 protease inhibition potential of functionalized polyoxometalates. Bioorg Med Chem Lett 2011, 21:1162-1166.

65. Ghosh AK, Chapsal BD, Parham GL, Steffey M, Agniswamy J, Wang YF, Amano M, Weber IT, Mitsuya H: Design of HIV-1 protease inhibitors with C3-substituted hexahydrocyclopentafuranyl urethanes as P2-ligands: synthesis, biological evaluation, and protein-ligand X-ray crystal structure. J Med Chem 2011, 54:5890-5901.

66. Ghosh AK, Chapsal BD, Steffey M, Agniswamy J, Wang YF, Amano M, Weber IT, Mitsuya H: Substituent effects on P2-cyclopentyltetrahydrofuranyl urethanes: design, synthesis, and X-ray studies of potent HIV-1 protease inhibitors. Bioorg Med Chem Lett 2012, 22:2308-2311.

67. Bouras A, Boggetto N, Benatalah Z, de Rosny E, Sicsic S, Reboud-Ravaux M: Design, synthesis, and evaluation of conformationally constrained tongs, new inhibitors of HIV-1 protease dimerization. J Med Chem 1999, 42: 957-962.

68. Shultz MD, Ham YW, Lee SG, Davis DA, Brown C, Chmielewski J: Smallmolecule dimerization inhibitors of wild-type and mutant HIV protease: a focused library approach. J Am Chem Soc 2004, 126:9886-9887.

69. Bowman MJ, Byrne S, Chmielewski J: Switching between allosteric and dimerization inhibition of HIV-1 protease. Chem Biol 2005, 12:439-444.

70. Bowman MJ, Chmielewski J: Novel strategies for targeting the dimerization interface of HIV protease with cross-linked interfacial peptides. Biopolymers 2002, 66:126-133.

71. Shultz MD, Bowman MJ, Ham YW, Zhao X, Tora G, Chmielewski J: SmallMolecule Inhibitors of HIV-1 Protease Dimerization Derived from CrossLinked Interfacial Peptides This work was supported by NIH (GM52739) and NSF (9457372-CHE). Angew Chem Int Ed Engl 2000, 39:2710-2713.

72. Hwang YS, Chmielewski J: Development of low molecular weight HIV-1 protease dimerization inhibitors. J Med Chem 2005, 48:2239-2242.
73. Cheng TJ, Brik A, Wong CH, Kan CC: Model system for high-throughput screening of novel human immunodeficiency virus protease inhibitors in Escherichia coli. Antimicrob Agents Chemother 2004, 48:2437-2447.

74. Cheng YS, Lo KH, Hsu HH, Shao YM, Yang WB, Lin CH, Wong CH: Screening for HIV protease inhibitors by protection against activity-mediated cytotoxicity in Escherichia coli. J Virol Methods 2006, 137:82-87.

75. Lindsten K, Uhlikova T, Konvalinka J, Masucci MG, Dantuma NP: Cell-based fluorescence assay for human immunodeficiency virus type 1 protease activity. Antimicrob Agents Chemother 2001, 45:2616-2622.

76. Fuse T, Watanabe K, Kitazato K, Kobayashi N: Establishment of a new cell line inducibly expressing HIV-1 protease for performing safe and highly sensitive screening of HIV protease inhibitors. Microbes Infect 2006, 8:1783-1789.

77. Hu K, Clement JF, Abrahamyan L, Strebel K, Bouvier M, Kleiman L, Mouland AJ: A human immunodeficiency virus type 1 protease biosensor assay using bioluminescence resonance energy transfer. J Virol Methods 2005, 128:93-103.

78. Cheng YS, Yin FH, Foundling S, Blomstrom D, Kettner CA: Stability and activity of human immunodeficiency virus protease: comparison of the natural dimer with a homologous, single-chain tethered dimer. Proc Natl Acad Sci U S A 1990, 87:9660-9664.

79. Patterson CE, Seetharam R, Kettner CA, Cheng YS: Human immunodeficiency virus type 1 and type 2 protease monomers are functionally interchangeable in the dimeric enzymes. J Virol 1992, 66:1228-1231

80. Takegawa K, Tohda H, Sasaki M, Idiris A, Ohashi T, Mukaiyama H, Giga-Hama $Y$, Kumagai $\mathrm{H}$ : Production of heterologous proteins using the fissionyeast (Schizosaccharomyces pombe) expression system. Biotechnol Appl Biochem 2009, 53:227-235

81. Zhao Y, Lieberman HB: Schizosaccharomyces pombe: a model for molecular studies of eukaryotic genes. DNA Cell Biol 1995, 14:359-371.

82. Giga-Hama $Y$, Kumagai $\mathrm{H}$ : Expression system for foreign genes using the fission yeast Schizosaccharomyces pombe. Biotechnol Appl Biochem 1999, 30(Pt 3):235-244.

83. Lu Q, Bauer JC, Greener A: Using Schizosaccharomyces pombe as a host for expression and purification of eukaryotic proteins. Gene 1997, 200:135-144.

84. Zhao Y, Elder RT: Yeast perspectives on HIV-1 VPR. Front Biosci 2000, 5: D905-916.

85. Li G, Bukrinsky M, Zhao RY: HIV-1 viral protein R (Vpr) and its interactions with host cell. Curr HIV Res 2009, 7:178-183.

86. Zhao RY, Elder RT: Viral infections and cell cycle G2/M regulation. Cell Res 2005, 15:143-149.

87. Zhao Y, Cao J, O'Gorman MR, Yu M, Yogev R: Effect of human immunodeficiency virus type 1 protein $R$ (vpr) gene expression on basic cellular function of fission yeast Schizosaccharomyces pombe. J Virol 1996, 70:5821-5826.

88. Zhao RY, Bukrinsky M, Elder RT: HIV-1 viral protein R (Vpr) \& host cellular responses. Indian J Med Res 2005, 121:270-286.

89. Zhao RY, Elder RT, Bukrinsky M: Interactions of HIV-1 viral protein R with host cell proteins. Adv Pharmacol 2007, 55:233-260.

90. Huard S, Chen M, Burdette KE, Fenyvuesvolgyi C, Yu M, Elder RT, Zhao RY: HIV-1 Vpr-induced cell death in Schizosaccharomyces pombe is reminiscent of apoptosis. Cell Res 2008, 18:961-973.

91. Benko Z, Elder R, Liang D, Zhao R: Fission yeast as a HTS platform for molecular probes of HIV-1 Vpr-induced cell death. Int J High Throughput Screen 2010, 1:151-162.

doi:10.1186/2045-3701-2-32

Cite this article as: Yang et al:: Effects of HIV-1 protease on cellular functions and their potential applications in antiretroviral therapy. Cell \& Bioscience 2012 2:32. 